\title{
Unusual Presentation of a Rare Giant Fibroadenoma of the Breast
}

\author{
J. Darido ${ }^{* \#}$, S. El Daou ${ }^{2}$, R. El Assaad1,3, A. Fakih4, M. Dagher1, A. Safa5 , N. Haddad1, H. Farhat ${ }^{2}$ \\ ${ }^{1}$ Department of Obstetrics and Gynecology, Lebanese University, Beirut, Lebanon \\ ${ }^{2}$ Department of General Surgery, Lebanese University, Beirut, Lebanon \\ ${ }^{3}$ Department of Obstetrics and Gynecology, Sahel General University Hospital, Beirut, Lebanon \\ ${ }^{4}$ Department of Dermatology, Governmental University Hospital of Baabda, Baabda, Lebanon \\ ${ }^{5}$ Department of Emergency Medicine, Rafic Hariri University Hospital, Beirut, Lebanon \\ Email: "jesydarido@hotmail.com
}

How to cite this paper: Darido, J., El Daou, S., El Assaad, R., Fakih, A., Dagher, M., Safa, A., Haddad, N. and Farhat, H. (2019) Unusual Presentation of a Rare Giant Fibroadenoma of the Breast. Journal of Cancer Therapy, 10, 717-721.

https://doi.org/10.4236/jct.2019.109059

Received: June 12, 2019

Accepted: August 30, 2019

Published: September 3, 2019

Copyright (c) 2019 by author(s) and Scientific Research Publishing Inc. This work is licensed under the Creative Commons Attribution International License (CC BY 4.0).

http://creativecommons.org/licenses/by/4.0/

\begin{abstract}
Giant fibroadenomas are exceptional in pregnancy and in most of cases, diameter doesn't reach more than $15 \mathrm{~cm}$. However, our case is a rare one that reached $18 \mathrm{~cm}$ in a 23-year-old female referred post-partum for evaluation of a huge left breast mass. On the other hand, there is a persistent debate regarding the best modality of the surgical approach to giant tumors; most of the experts recommend the enulceation of the tumor after delivery while others argue that extirpation during pregnancy is the best since we have to exclude malignancy. In our patient, the whole tumor was excised at the postpartum period and the pathology did not show any sign of malignancy. Even if our case does not clearly reveal the long term result of the postpartum excision of a giant fibroadenoma, the short term result we have had after this approach was satisfying. Further studies are important to be published in order to confirm pros and cons of the postpartum approach.
\end{abstract}

\section{Keywords}

Fibroadenomas, Breast Disease, Pregnancy, Surgery, Postpartum

\section{Introduction}

Fibroadenomas are benign solid breast tumors of unknown etiology that contain both glandular and fibrous tissue. They are usually small and consequently can be treated conservatively. However, up to $2 \%$ of fibroadenomas will show a rapid growth reaching the stage of giant fibroadenoma with an important breast deformity where malignancy is highly suspected and cannot be excluded. Giant fi*Same contribution. 
broadenomas refer to fibroadenomas that are over $10 \mathrm{~cm}$ in size, that are usually managed surgically. These tumors are very rare and in most of cases, their diameter doesn't reach more than $15 \mathrm{~cm}$ [1]. Fibroadenomas undergo lactational histologic changes during pregnancy along with increase in size [2]. We hereby present the case of a fibroadenoma of the breast that reached $18 \mathrm{~cm}$.

\section{Case Presentation}

This is a 23-year-old lady who was referred post-partum by her gynecologist to the general surgery department for evaluation of a huge left breast mass that started at first with a $1 \mathrm{~cm}$ lesion at the fifth month of pregnancy and continued to grow till a diameter of $18 \mathrm{~cm}$ three months postpartum (Figure 1).

Note that during the pregnancy, her obstetrician decided not to perform any invasive procedures over the tumor but advised her to seek a general surgeon's opinion immediately after delivery. However, she was lost of view until three months postpartum.

The patient underwent a normal vaginal delivery and had a healthy baby; note that she has neither a past medical nor a past surgical history. The mass was non-painful and mobile with no history of breast secretions. Due to its large size, the patient started suffering from dyspnea and back pain. Ultrasound did not show any signs of malignancy. A partial mastectomy was performed and the tumor was completely excised. The healthy tissue was preserved along with the nipple-areola complex. Intraoperative frozen section showed a lactating adenoma and the excised tumor weighted 1590 grams. The definitive pathology results showed a proliferation of multiple dilated and cystic galactophoric ducts lined by flat or hyperplastic epithelium, separated by fibrotic and myxoid stroma surrounded by an inflammatory infiltrate with secretions in the lamina. These pathological findings indicated a diagnosis of fibradenoma (Figure 2).

Seen at three months post operatively, the patient did not have any recurrence and the esthetical results were satisfying (Figure 3 ).

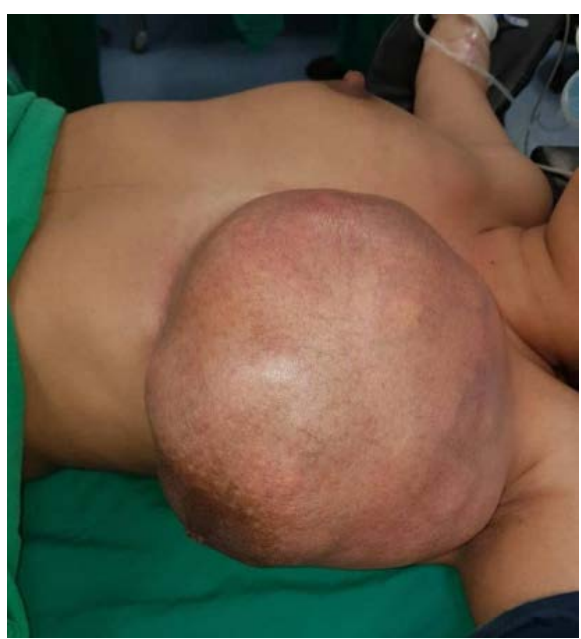

Figure 1. Preoperative breast image, note the asymmetry and the huge left breast mass. 


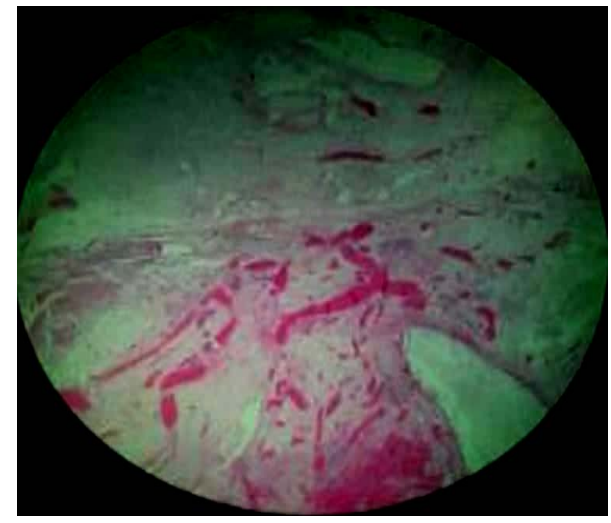

Figure 2. The definitive pathology result.

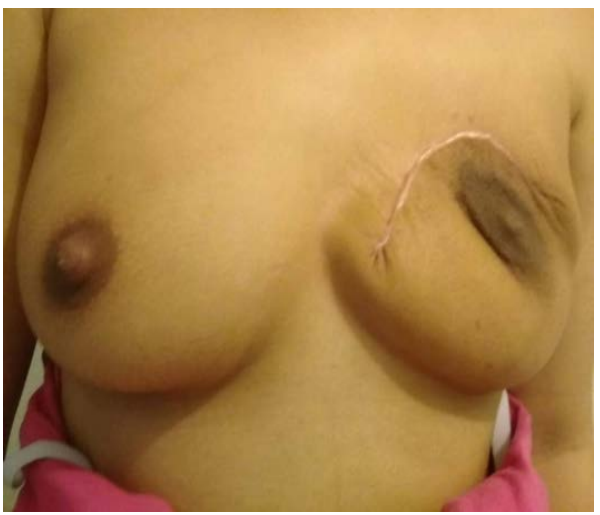

Figure 3. Postoperative breast image, with acceptable symmetry and complete excision of the tumor.

\section{Discussion}

Giant fibroadenomas are benign breast tumors that constitute approximately $5 \%$ of all breast tumors and $0.5 \%-2 \%$ of all cases of fibroadenomas [3]. They are unilateral in $90 \%$ of cases, and usually occur in the upper outer quadrant and vary in size from less than $1 \mathrm{~cm}$ to $20 \mathrm{~cm}$ [4]. Unlike simple fibroadenomas, giant fibroadenomas are exceptional during pregnancy and only three cases $>15$ $\mathrm{cm}$ have been reported in the literature. In our case, the size of the mass reached $18 \mathrm{~cm}$.

Giant fibroadenomas are mainly seen in the $2^{\text {nd }}$ and $3^{\text {rd }}$ decade of life in Asian and African patients [5]. The differential diagnosis of fibroadenoma is very wide but phyllodes tumors are the most important ones and it seems that fine needle aspiration and ultrasound are not effective in differentiating them. In fact, the surgical excision is the best means for diagnosing this lesion. It is crucial to differentiate these lesions because there is more risk for malignancy in phyllodes and therefore, the management will be different [1]. Our patient belonged to the typical age group but unlike the literature she belonged to the Caucasian race.

There is still a debate regarding the best modality for surgical management of giant tumors during pregnancy. Most of the experts recommend the enulceation of the tumor after delivery while others argue that extirpation during pregnancy 
is the best modality to exclude malignancy [6]. In the case of our patient, we excised the whole tumor postpartum and the pathology did not show any sign of malignancy. The diagnosis of giant breast tumors during pregnancy is wide, and malignancy should always be ruled out. Ultrasound, FNA and MRI can be considered as useful modalities to rule out malignancy [7]. Some authors consider that the enucleation of the tumor after delivery, as it was done in our case, is the best surgical approach to avoid the effects of general anesthesia of both the mother and the baby [6]. However, other authors consider that because of the progressive structural damage of the breast an immediate surgical enucleation is indicated in this case. In fact, Heilman et al. reported a case of a 17-year-old la$\mathrm{dy}, 24$ weeks gestation, diagnosed with a $10 \mathrm{~cm}$ fibroadenoma in the right breast where a lumpectomy was immediately performed with no complication upon the ongoing pregnancy and where the safety of the fetus was provided by perioperative monitoring [7].

\section{Conclusion}

Even if this single case, as it is presented, doesn't show the long term result of different timings of surgical approaches. The result of the operation done after delivery was satisfying. Further studies are important to be published in order to confirm pros and cons of the postpartum approach in comparison with the one done during pregnancy.

\section{Funding}

No source to be stated.

\section{Consent}

Written consent has been taken from the patient for publication of this report.

\section{Conflicts of Interest}

The authors declare no conflicts of interest regarding the publication of this paper.

\section{References}

[1] Sabel, M.S. (2013) Overview of Benign Breast Disease. UpToDate.

[2] Raganooonan, C., Fairbairn, J.K., Williams, S. and Hughes, L.E. (1987) Giant Breast Tumors of Adolescence. Australian and New Zealand Journal of Surgery, 57, 243-247. https://doi.org/10.1111/j.1445-2197.1987.tb01348.x

[3] McCague, A. and Davis, J.V. (2010) Giant Fibroadenoma in a 22 Year Old Patient: Case Report and Literature Review. Breast Disease, 31, 49-52. https://doi.org/10.3233/BD-2009-0288

[4] Park, C.A., David, L.R. and Argenta, L.C. (2006) Breast Asymmetry: Presentation of a Giant Fibroadenoma. The Breast Journal, 12, 451-461. https://doi.org/10.1111/j.1075-122X.2006.00303.X

[5] Karagulle, E., Turk, E., Erinanc, O.H. and Moray, G. (2014) Giant Fibroadenoma 
Growing Rapidly during Pregnancy. Iranian Red Crescent Medical Journal, 16, e9531. https://doi.org/10.5812/ircmj.9531

[6] Greenberg, R., Skornick, Y. and Kaplan, O. (1998) Mangement of Breast Fibroadenomas. Journal of General Internal Medicine, 13, 640-645. https://doi.org/10.1046/j.1525-1497.1998.cr188.x

[7] Heilmann, T., et al. (2012) Diagnosis and Management of an Unilateral Giant Fibroadenoma of the Breast in Pregnancy. Archives of Gynecology and Obstetrics, 285, 235-237. https://doi.org/10.1007/s00404-011-1923-9 